\title{
Herman Hummel \\ Geographical patterns of dominant bivalves and a polychaete in Europe: no metapopulations in the marine coastal zone?
}

Received: 4 February 2002 / Revised: 27 May 2002 / Accepted: 21 June 2002 / Published online: 5 December 2002

(C) Springer-Verlag and AWI 2002

\begin{abstract}
The genetic diversity, differentiation and performance of some dominant invertebrates in the marine coastal zone of Europe are reviewed in order to discuss the use of the metapopulation concept in the marine coastal realm. A consistently high genetic diversity of the species studied (mussels of the Mytilus edulis complex, Baltic clams Macoma balthica and lugworms Arenicola marina), a low differentiation and an almost uniform ecophysiological performance (determined by growth, maximum length, level reserve constituents or stress resistance) all along the coast of Europe do not support the use of the metapopulation concept.
\end{abstract}

Keywords Clams · Mussels · Lugworm ·

Metapopulation · Genetic diversity · Differentiation ·

Ecophysiology

\section{Introduction}

In the metapopulation concept, extinction/recolonization processes within an assemblage of populations play a central role (Hanski and Simberloff 1997). According to the classical concept, the exchange rates (migration, transfer) between local populations are assumed to be so small that the local population dynamics show stronger fluctuations (and are faster) than in the entire (persistent) assemblage. Therefore, the local populations have a serious risk of extinction. Although the concept has been adapted during the last two decades, the mechanisms of extinction, migration from other local populations in a

Communicated by W. Armonies, M. Strasser and K. Reise

H. Hummel (

Centre for Estuarine and Marine Ecology,

Netherlands Institute of Ecology (NIOO-CEME),

Royal Netherlands Academy of Arts and Sciences,

Korringaweg 7, PO Box 140, 4400 AC Yerseke, The Netherlands e-mail: h.hummel@nioo.knaw.nl

Tel.: +31-113-577484, Fax: +31-113-573616 persistent assemblage, and recolonization, are still basic components.

The validity of the metapopulation concept for invertebrate organisms in the marine environment has already been questioned (Harrison and Taylor 1997), since the planktonic larvae of marine invertebrates show a high migration, whereby the range of migration overrides the size of the local patch and maybe even that of the assemblage.

In this paper I discuss some features in marine organisms that we can study in order to accept or refute the concept for some dominant key species in the marine coastal area, and finally reaching a conclusion on whether we should endorse or reject the applicability of the metapopulation concept to the marine coastal realm.

Accepting that migration between local populations is small, and major extinction events are happening, it may be appropriate to study the degree of diversity within, and differentiation between, populations. This first set of (genetic) features can be assessed by genetic studies, of which I present some examples.

In a metapopulation with a high number of patches, a lower diversity $(H)$ within the populations, yet higher differentiation between populations $(F$ st) is to be expected (Hedrick and Gilpin 1997; Barton and Whitlock 1997). With an increase in gene flow between populations, however, the diversity increases and differentiation decreases, i.e. there is ultimately no longer an assemblage of local populations but a homogeneous panmixic population.

A second set of features in marine organisms can be compiled using the performance capacity model. Going towards the edge of a patch (local population), the habitat becomes less and less favourable for the organisms, and thus their performance (e.g. fitness or growth) becomes gradually poorer. Beyond the border of the patch the environmental conditions may be lethal.

In the case of local populations within a larger assemblage, we expect an alternation of sites where the organisms flourish or perish. Along a geographical gradient we will then find specimens of the same species with 
highly variable performance (in the centre of a patch optimal, at the edge minimal). In another year the situation may be different (some local populations may have perished). In cases where we find only a gradual change or even a similar performance everywhere over many years, this would indicate a continuum and the absence of local populations.

The aim of this paper, therefore, is to assess (genetic, ecophysiological) patterns in the geographic distribution of distinct groups (ecotypes, races, subspecies) of some dominant species along the European coastal marine area, i.e. in the mussel Mytilus edulis complex, the Baltic clam Macoma balthica, and the lugworm Arenicola marina, in order to test whether (changes in) their distribution is in accordance with the metapopulation concept.

To this end, I review for the above marine species along the European coastline:

- the distribution (borders), genetic diversity and differentiation within and between populations, and

- the variation in the performance capacity, determined as the growth rate, weight index, or stress resistance, of (seemingly) the same species in different areas.

\section{Materials}

The reviewed studies were primarily performed during the last decade in the context of the question: what kind of adaptations occur in dominant marine invertebrates under the influence of extreme and/or stressing environmental conditions? This resulted in an overview of the genetic diversity, the genetic differentiation and the differences in (ecophysiological) performance between populations: features that can be used when investigating the possible existence of metapopulations for some dominant benthic invertebrates in marine coastal areas.

Specimens of the mussel Mytilus edulis complex, the clam Macoma balthica and the lugworm Arenicola marina, from locations all over Europe have been sampled and analysed (Fig. 1).

The genetic features are based on isoenzyme electrophoretic analyses, and the methods and results are described in Hummel et al. (1997a - Baltic clam Macoma balthica; 1997b - lugworm Arenicola marina; 2001 - mussel Mytilus edulis complex). The genetic diversity is indicated by the heterozygosity $H$, the genetic differentiation by the fixation index $F$ st.

The performance characteristics have been encompassed in the performance capacity model (Schreck 1981; Fig. 2). This model is the visualization of an individual or population its (genetic) potential and realized capacity (which is lower than the potential because of energy-consuming adjustments in response to the lessthan-optimal environment). The performance is reflected in features such as weight, growth, fitness, stress resistance and reproduction.

Where additional stressors are present, the performance may be further reduced, since energy is needed to withstand the stressor. At the limit of distribution the performance capacity is thought to be even further reduced due to out-selection of some ecotypes and almost lethal conditions (Fig. 2).

All the features mentioned, and especially their combination, may help to define limits between local populations that should have their own dynamics. If the metapopulation concept would be useful for marine organisms we should expect (1) high values for genetic differentiation, (2) low values for genetic diversity, and (3) for performance capacity we would expect alternating high (in centres of local populations) and low values (at borders) along a geographic gradient.

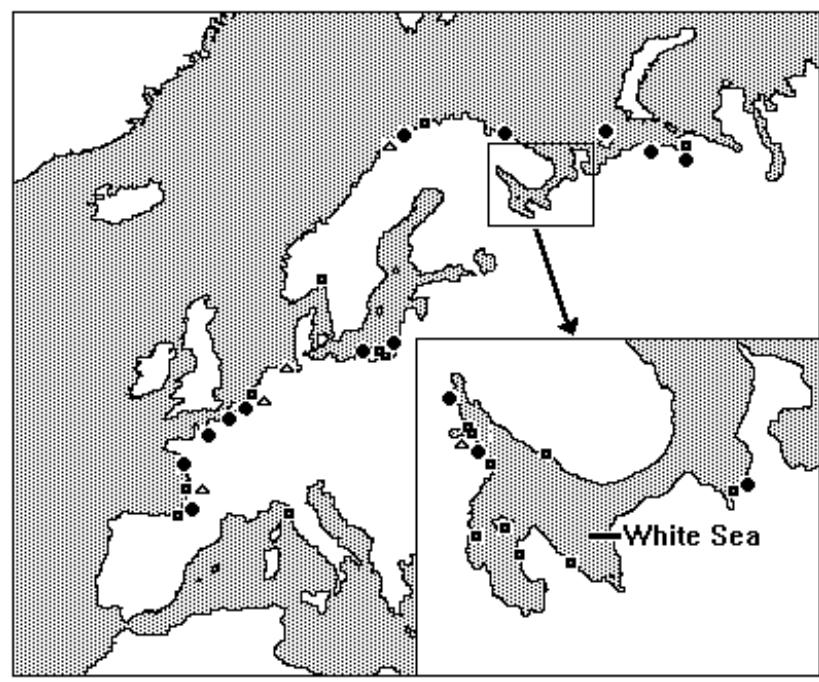

Fig. 1 Sampling stations of mussels Mytilus edulis complex (open squares), clams Macoma balthica (filled circles), and lugworms Arenicola marina (open triangles) in Europe

\section{Performance capacity}

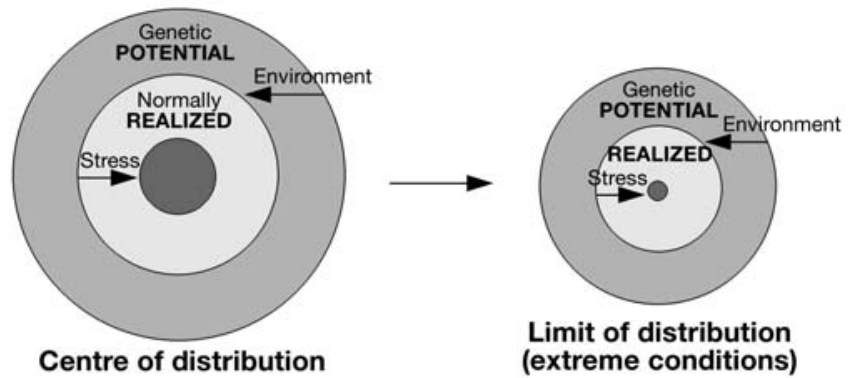

Fig. 2 The performance capacity model (adapted from Schreck 1981; Hummel et al. 1997a). The left side of the model visualizes the basic idea that an organism (or population) normally does not reach its genetically determined potential maximum performance (as maximum growth or fitness), since a fully optimal environment never surrounds it. The right side shows the situation near a species' limit of distribution where some genetic variants are lost and the performance consequently reduces further

\section{Results and discussion}

Genetic diversity and differentiation

Mussels and clams can be genetically divided into major groups (clusters) of races or subspecies (Figs. 3, 4; Hummel et al. 1997a, 2001). A similar geographical distribution of the major groups in both species is apparent. Limits between the major groups can be found near the same locations, i.e. SW France and the entrance of the Baltic Sea.

Within the groups the genetic diversity $(H)$ was very high all over Europe with only small latitudinal differences. This consistently high diversity does not support the existence of many patches with (sub)populations. 


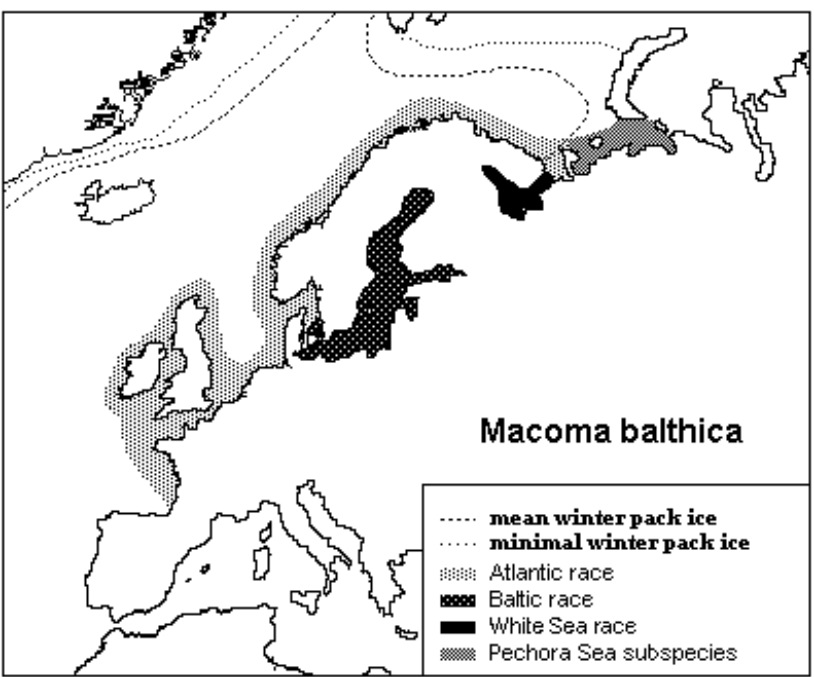

Fig. 3 The distribution of races and subspecies of Macoma balthica in Europe

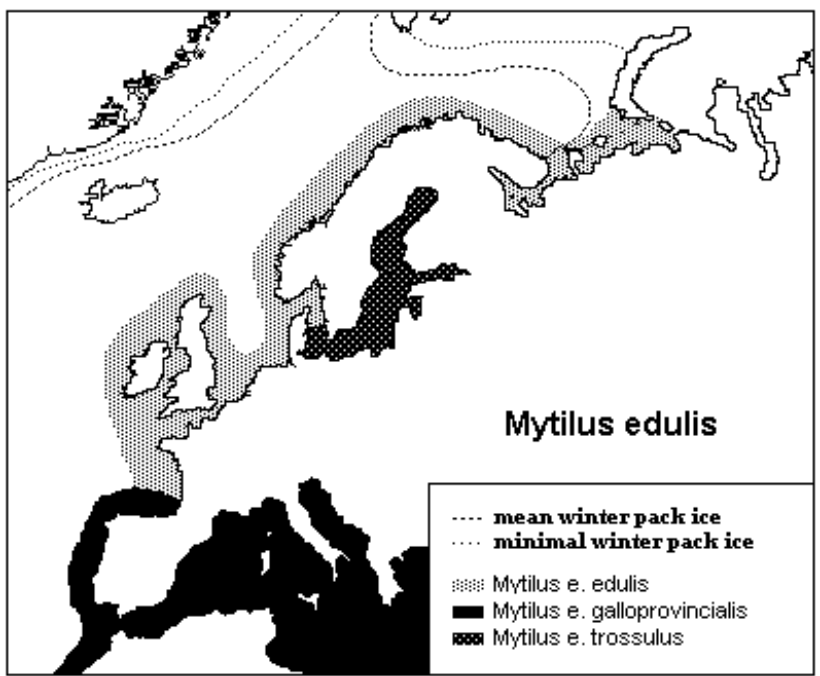

Fig. 4 The distribution of (sub)species of the Mytilus edulis complex in Europe

For clams (Fig. 5) as well as mussels, the value of $H$ increases only slightly in northern territories. The latitudinal variation in diversity probably has nothing to do with variations in patchiness of the populations but could be related to the impact of environmental conditions, i.e. temperature. The diversity $H$ is linked to the allelic variation (frequencies of alleles). At locations with lower temperatures the diversity (as indicated by the allelic variation) increased, as observed for the isoenzyme isocitrate dehydrogenase (Idh) gene in clams: the frequency of allele $\mathrm{C}$ increased, and that of allele $\mathrm{B}$ decreased, with lower temperatures (Fig. 6). These clines could be found at distances of tens of metres when comparing populations along a vertical gradient, whereas along a horizon-
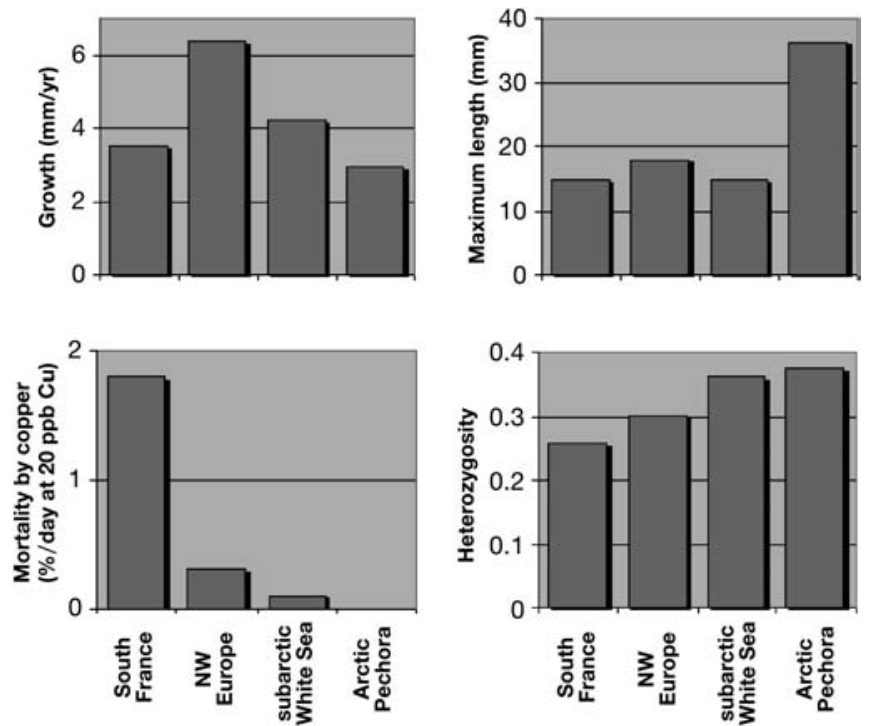

Fig. 5 The performance and genetic diversity (heterozygosity, $H$ ) of Macoma balthica in Europe (after Hummel et al. 1997a, 1998a) (mortality by copper not measured in Pechora population)

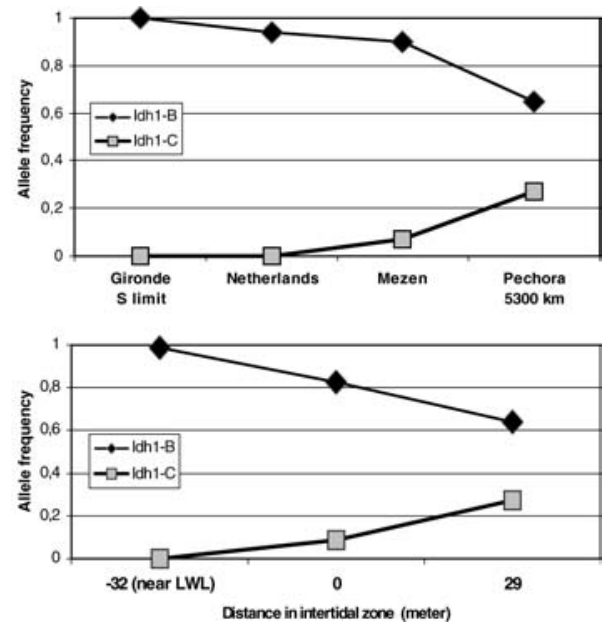

Fig. 6 Clines of genetic diversity along a horizontal geographic gradient (upper part) and along a vertical gradient (at polar circle, Kartesh, Russia: 0=MTL), as indicated by allele frequencies in the clam Macoma balthica (after Hummel et al. 1997a, 1998b)

tal gradient the distance between populations would be hundreds or even thousands of kilometres (Fig. 6). Thus the cause of variation in diversity is obviously selection by temperature within a further homogeneous population.

Remarkably, a similar cline of diversity, related to temperature (Fig. 7), and a similar distribution of major genetic groups can be found in another dominant marine organism from a completely different taxon: the lugworm Arenicola marina (Hummel et al. 1997b).

A homogeneous distribution was also indicated by the very low genetic differentiation $(F \mathrm{st})$ for clams, as for mussels. Within the major groups the $F$ st for clams in Europe was only $0.03-0.08$ (even when all populations 


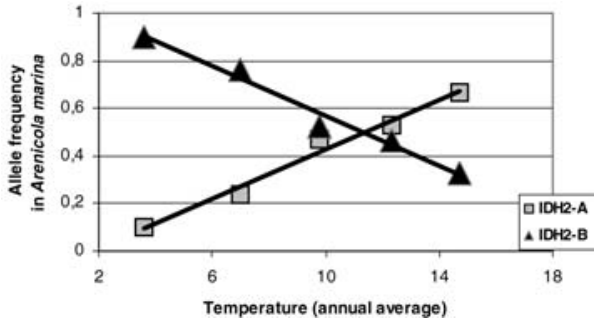

Fig. 7 Cline of genetic diversity indicated by allele frequencies of the isoenzyme isocitrate dehydrogenase (Idh) along a horizontal geographic gradient in Europe (expressed as the annual average temperature; from polar circle, Kartesh, Russia, to Gironde, SW France) in the polychaete lugworm Arenicola marina (after Hummel et al. 1997b)

were taken together, including the geographically most extreme populations, the $F$ st in Europe was only 0.11 for clams; Hummel et al. 1997a), and within the subspecies of the mussel complex it was only 0.02-0.06 (Hummel et al. 2001). In contrast, the genetic differentiation of the cockle Cerastoderma glaucum, which with a lower gene flow is more or less restricted to lagoons, was as high as 0.19 even though it was on a much smaller geographical scale (i.e. not including northern Europe) (Hummel et al. 1994).

This homogeneous distribution may be the result of a widespread transport of larvae, drifting for several weeks in the open coastal waters (along NW Europe by the Gulf Stream). Moreover, human activities such as oyster or mussel culture will also favour a homogeneous distribution. The consequence may be a continuous mixing of the populations (gene flow), resulting in large homogeneous groups along the western and northern European coastline. Again this does not support the usefulness of the metapopulation concept.

\section{Performance capacity}

The performance capacity in clams and mussels was estimated at an ecophysiological level, e.g. by measuring growth rates, maximum length, level of reserve constituents and stress resistance. The division of groups with similar performance characteristics coincided exactly with the differentiation on the basis of the genetic constitution (Hummel et al. 1998a, 2001).

Within the genetic groups (subspecies or races), gradual clines (geographical gradients) of the measured performance features could be found. As expected, according to the performance capacity model, a lower performance was found at the limits of a species' distribution. This was especially true in SW France, the southernmost limit of the clam M. balthica (Fig. 5). Although clearly belonging to the Atlantic race, the population there showed a reduced and strongly deviating performance.

A slightly reduced performance, although not for the stress resistance, was also found in the subarctic White Sea. However, on the other hand, a remarkably good per- formance was observed in the Arctic. This is most probably due to the presence of another subspecies, at least for clams (Fig. 3), as a consequence of isolation by pack-ice whereby exchange with populations of the other subspecies has been lost. This Arctic group thus does not belong to the assemblage of Atlantic and White Sea populations.

Although some variance in the performance of the studied bivalves has been found, only at one place and for one species (i.e. clams in SW France) is it so obvious and strongly reduced that it can be determined and conforms to the performance capacity model (Fig. 2, right). For Baltic clams, the very edge of this species' distribution is found in SW France.

Further along the European coastline, at all places studied, the variance in performance is moderate for both bivalve species, and specimens of several year-classes were always found during the last 10 years. This does not support the existence of a metapopulation with patches of populations becoming extinct or being recolonized.

\section{Conclusion}

The absence of a strong variance in genetic diversity and (ecophysiological) performance, and the low genetic differentiation of dominant marine coastal invertebrates do not indicate isolated populations along the European coastline. As well as the absence of a strong spatial variance, no strongly changing patterns can be found at the relevant temporal scales as indicated by the phenomena that we have been observing, from the genetic features, with longer (evolutionary) time scales, to the physiological and ecological features, with seasonal or annual scales. Therefore, for the studied species, the paradigms essential in the metapopulation concept (i.e. extinction-migration-recolonization of local populations) cannot be shown at the relevant spatial and temporal scales. Only at the borders of the (sub)species (or species complexes) were some stronger variations in performance, which may indicate populations that could become extinct or be recolonized.

The features determined in the dominant marine invertebrates merely support the idea of a continuum of strongly interconnected populations, i.e. one homogeneously mixed gene-pool. The moderate variance in performance and diversity is thought to be primarily governed by the gradually acting impact of environmental factors.

Therefore, restrictions in migration, and the existence of extinct and/or recolonized populations are not realistic phenomena for the dominant marine coastal invertebrates described in this paper, whereby the concept of metapopulations is not useful. Only at the border of these species' distributions may the presence of metapopulations be feasible.

It is my conclusion that for the dominant marine coastal invertebrates in Europe the concept of metapopu- 
lations is not useful. These large homogeneous groups could better be termed mega-populations.

Acknowledgements The author is much indebted to the support by AWI, and in particular to the input and patience of Karsten Reise, Matthias Strasser and Werner Armonies. This is contribution no. 3079 of the Netherlands Institute of Ecology.

\section{References}

Barton NH, Whitlock MC (1997) The evolution of metapopulations. In: Hanski I, Gilpin ME (eds) Metapopulation biology. Ecology, genetics and evolution. Academic Press, San Diego, pp 183-210

Hanski I, Simberloff D (1997) The metapopulation approach, its history, conceptual domain, and application to conservation. In: Hanski I, Gilpin ME (eds) Metapopulation biology. Ecology, genetics and evolution. Academic Press, San Diego, pp 5-26

Harrison S, Taylor AD (1997) Empirical evidence for metapopulation dynamics. In: Hanski I, Gilpin ME (eds) Metapopulation biology. Ecology, genetics and evolution. Academic Press, San Diego, pp 27-42

Hedrick PW, Gilpin ME (1997) Genetic effective size of a metapopulation. In: Hanski I, Gilpin ME (eds) Metapopulation biology. Ecology, genetics and evolution. Academic Press, San Diego, pp 165-181
Hummel H, Wolowicz M, Bogaards RH (1994) Genetic relations between populations of Cerastoderma edule and C. glaucum. Neth J Sea Res 33:81-89

Hummel H, Bogaards R, Bek T, Polishchuk L, Amiard-Triquet C, Bachelet G, Desprez M, Strelkov P, Sukhotin A, Naumov A, Dahle S, Denisenko S, Gantsevich M, Sokolov K, Wolf L de (1997a) Sensitivity to stress in the bivalve Macoma balthica from the most northern (Arctic) to the most southern (French) populations: low sensitivity in Arctic populations because of genetic adaptations? Hydrobiologia 355:127-138

Hummel H, Sommer A, Bogaards RH, Pörtner HO (1997b) Variation in genetic traits of the lugworm Arenicola marina: temperature related expression of mitochondrial allozymes? Mar Ecol Prog Ser 159:189-195

Hummel H, Bogaards R, Bek T, Polishchuk L, Sokolov K, Amiard-Triquet C, Bachelet G, Desprez $M$, Naumov A, Strelkov P, Dahle S, Denisenko S, Gantsevich M, Wolf L de (1998a) Growth in the bivalve Macoma balthica from its northern to its southern distribution limit: a discontinuity in North-Europe because of genetic adaptations in Arctic populations? Comp Biochem Physiol A 120:133-141

Hummel H, Günther CP, Bogaards RH, Fedyakov V (1998b) Variation in genetic traits of the Baltic clam Macoma balthica from a tidal gradient in the subarctic. Polar Biol 19:342-347

Hummel, H. Colucci F, Bogaards RH, Strelkov P (2001) Genetic traits in the bivalve Mytilus from Europe, with an emphasis on Arctic populations. Polar Biol 24:44-52

Schreck CB (1981) Stress and compensation in Teleostean fishes: responses to social and physical factors. In: Pickering AD (ed) Stress and fish. Academic Press, London, pp 295-321 